\title{
AS INSTITUIÇõES DE ENSINO: DESAFIOS PARA A MEMÓRIA ${ }^{1}$
}

\author{
TEACHING INSTITUTIONS: CHALLENGES FOR MEMORY
}

\author{
Gleison Peralta Peres \\ Pontifícia Universidade Católica de Goiás, Goiânia, GO, Brasil. E-mail: gleisonpp@hotmail.com \\ https://orcid.org/0000-0002-8246-8613
}

DOI: https://doi.org/10.46550/amormundi.v1i2.26

Recebido em: 23.09.2020

Aceito em: 02.11.2020

Resumo: Este texto é uma revisão de literatura que aborda as questôes relacionadas a conceito de memória institucional, com foco as instituiçôes escolares. No segundo momento abordamos a memória e seu papel na história. Por fim acreditamos que este texto possa contribuir com a temática.

Palavras-chave: Educação. Memória institucional. Instituiçôes escolares.

Abstract: This text is a literature review that addresses issues related to the concept of institutional memory, focusing on school institutions. In the second moment, we approach memory and its role in history. Finally, we believe that this text can contribute to the theme.

Keywords: Education. Institutional memory. School institutions.

\section{Introduçáo}

$\Lambda$ definição de instituições, principalmente para a própria história institucional, é

Afundamental, pois pode revelar diversos posicionamentos institucionais ao longo da trajetória da instituição, pois as pessoas passam e a instituição fica.

É fundamental conhecermos como a memória pode transformar ambientes e propor realidades distintas do passado, por isso a necessidade do conhecimento através da memória. Acreditamos que esse texto possa contribuir com pesquisadores da área, dado a dificuldade de encontrar textos que abordem essa temática.

\section{Instituiçóes: conceito}

A definição da palavra "instituição", que segundo Torrinha (1945, p. 434) deriva-se do latim institutio, onis, é vocábulo que apresenta uma variação de significados que podem ser agrupados em quatro acepçôes: "1. Disposição; plano; arranjo. 2. Instrução; ensino; educação. 3. Criação; formação. 4. Método; sistema; escola; seita; doutrina”.

1 Este texto é um recorte do primeiro capítulo da pesquisa de Mestrado em História da Pontifícia Universidade Católica de Goiás, defendida em 20 de fevereiro de 2019, pelo autor do texto, porém foi revisado e atualizado para esta publicaçáo. 
Como percebemos, a definição de instituição é complexa, optamos pela definição referente ao item 4 (citado no parágrafo anterior segundo Torrinha), mas não desconsideramos o que Saviani (2005, p. 28) descreve:

[...] quarta acepção retém a ideia de coesão, de aglutinação em torno de determinados procedimentos (método); de determinados elementos distintos formando uma unidade (sistema); de certas idéias compartilhadas (escola, aqui, no sentido de um grupo de indivíduos reunidos em torno de um mestre ou orientação teórica, como nas expressões "escola filosófica", "escola de Frankfurt", "escola dos Annales"); de uma crença e rituais comuns (seita); ou de um conjunto coerente de idéias que orientam a conduta (doutrina).

A expressão definida por Torrinha (1945), apesar dos inúmeros significados que definem instituição, com o passar do tempo, vão se modificando e dando novos significados às definiçóes que os próprios indivíduos buscam descrever; porém, Saviani (2005) afirma que, nem todas as afirmações podem ser consideradas, pois a mudança de concepção deve ser considerada em consonância com o momento histórico que está relacionada.

A definição de instituição que propomos explicitar, é a que está relacionada ao ensino, proposta na definição proposta por Saviani (2005).

Como percebemos, a instituição se apresenta como uma estrutura material que se constitui primordial no sentido de atender as diversas necessidades, sejam elas culturais ou sociais,-principalmente as de caráter permanente, legitimando e delegando o papel institucional que ora representa.

Cabe ressaltar que as transitoriedades, nas instituiçôes, são firmadas posteriormente ao tempo cronológico, as mudanças de concepção e definição, vão depender do tempo histórico. As instituiçóes são criadas como "unidades de ação" que segundo Saviani (2005, p. 28), podem modificar o próprio funcionamento pelos agentes envolvidos.

[...] instituiçôes são, portanto, necessariamente sociais, tanto na origem, já que determinadas pelas necessidades postas pelas relaçóes entre os homens, como no seu próprio funcionamento, uma vez que se constituem como um conjunto de agentes que travam relaçóes entre si e com a sociedade a que servem.

Como podemos perceber o trabalho das instituiçôes sociais tem a prerrogativa institucional de produzir e reproduzir as ideias de determinados grupos sociais, sejam eles professores/as, estudantes ou equipe técnica. Para buscar implantar e disseminar suas ideias, as instituiçôes proporcionam uma identidade institucional que perpassa os indivíduos, e se tornam itens fundamentais para entender o processo de constituição e encaminhamentos institucionalizados.

Cabe destacar a ação humana consciente de Hobsbawn (1998, p. 50), pois é através dos agentes sociais que buscam aliar as necessidades reais com propostas a longo prazo.

[...] a maior parte da ação humana consciente, baseada em aprendizado, memória e experiência, constitui um vasto mecanismo para comparar constantemente passado, presente e futuro. As pessoas náo podem evitar a tentativa de antever o futuro mediante alguma forma de leitura do passado.

Apesar de concentrarmos esforços para identificar e consolidar a ideia de instituição cabe destacar que é fundamental o reconhecimento do período histórico vivenciado pelos indivíduos, onde o papel do historiador é identificar e posicionar sua narrativa diante das mudanças. Bourdieu e Passeron (1975, p. 64) descrevem, que a função institucional pode, inclusive, refletir 
na cultura dos grupos envolvidos em cada instituição.

Todo sistema de ensino institucionalizado (SE) deve as características específicas de sua estrutura e de seu funcionamento ao fato de que lhe é preciso produzir e reproduzir, pelos meios próprios da instituição, as condiçóes institucionais cuja existência e persistência (auto reprodução da instituição) são necessários tanto ao exercício de sua função própria de inculcação quanto à realização de sua função de reprodução de um arbitrário cultural do qual ele não é o produtor (reprodução cultural) e cuja reprodução contribui à reprodução das relaçóes entre os grupos ou as classes (reprodução social).

Saviani (2005) afirma que, as mudanças estruturantes no próprio sistema proposto por Bourdieu e Passeron (1975) vão proporcionar a concepção das instituiçôes de ensino, com suas características individualizadas, já que a institucionalização e a necessidade de formação da instituição são necessárias para a memória dos grupos.

Para Werle (2004, p. 111), a instituição, de forma ampla e detalhada que Saviani (2005) descreve, são espaços individuais, porém, lugares de ação social material como espaço subjetivo e de poder institucionalizado pertencente a determinado grupo.

As instituiçóes são lugares de ação sociais e como tal, marcados pelo tempo, espaços e pessoas, são formas sociais dotadas de organização jurídica e material, cujo estudo envolve a análise de suas origens, gênese, estabilidade, rupturas e processos de formação. Elas são o espaço real, tanto objetivo como subjetivo, no qual vivenciamos relaçóes, valores, normas, poder, experiências de lideranças, rivalidades, conflitos e competição.

A definição de instituição na percepção de Werle (2004, p. 112) é baseada em espaços objetivos e subjetivos. Estes podem ser considerados como espaço simbólico material, com intuito de permitir a organização, observação e descrição representativa, já que as instituições (no caso as de ensino) têm espaço físico demarcado com regras e organização definidas e institucionalizadas que podem se transformar em memória coletiva institucionalizada. Cabe ao historiador observar os nuances e descrever com instrumentos e métodos adequados, proporcionando modificar a realidade e compreender que cada tempo histórico tem suas particularidades.

Por outro lado, as instituições são também um espaço subjetivo, pois se reconstroem na memória a partir das relaçóes vividas em tempos e espaços definidos, compreendidos e rememorados a partir das subjetividades particulares dos que nelas viveram e se relacionaram. Sáo um espaço subjetivo, pois embora as dimensôes de continuidade e duração lhe sejam muito evidentes, nelas também se inscrevem relaçóes de autonomia, de liberdade, na medida em que há uma pluralidade de modos de pertencimento e maneiras de interagir que produzem compreensôes diferenciadas acerca da própria instituição.

Percebemos que as instituiçóes como espaço subjetivo, é uma forma de designar o substrato não material das instituiçóes dos quais as pessoas que fazem parte podem realizar as mudanças e que podem disseminar suas características, sejam elas individuais ou coletivas, conforme Mezzano (1998, p. 37).

A história está conformada por histórias de vida singulares, que transcorrem no seio das instituiçóes. Nelas se entrelaçam acontecimentos de trabalho, questóes de poder, vínculos libidinais individuais e grupais, inseridos na cultura recortada de cada organização em particular [...].

Como afirmou Mezanno (1998), as histórias de singularidades perpassam-se pelas 
instituiçóes e ocupam-se da memória institucional que busca abordar relatos históricos, que utilizem a narrativa ${ }^{2}$ para sua constituição e reconhecimento, valorizando assim, a subjetividade do espaço e dos indivíduos nela constituídos.

Identificamos que, para a materialização das instituiçôes, a memória deve estar presente, já que perpassa inúmeras geraçóes e a necessidade de constituir uma memória institucional deve refletir a trajetória dos indivíduos nela envolvida, como reprodutores no seu meio social, como afirma Costa (1997, p. 145).

[...] um elemento primordial no funcionamento das instituiçôes. É através da memória que as instituiçóes se reproduzem no seio da sociedade, retendo apenas as informações que interessam ao seu funcionamento. Há um processo seletivo que se desenvolve segundo regras instituídas e que variam de instituição para instituição. Tendo em vista que as instituiçóes funcionam em rede no campo social, o limite de uma instituição é outra instituição.

A trajetória de uma instituição é construída no seu cotidiano, e a concepção dialógica deve permear como instrumento de pensamento remetido às lembranças que podem ser individuais ou coletivas. Conhecer os princípios da memória e como são constituídos, é fundamental para seu entendimento.

\section{Memória institucional}

Tanto a memória quanto a história são conceitos aparentemente distintos, mas cada termo persiste com suas particularidades; e, para materializar a história através da memória, é um desafio historiográfico que iremos buscar ao dialogar e compreender as particularidades e as convergências.

A memória é parte integrante de nossas vidas, armazenamos as inúmeras experiências vividas e ouvidas ao longo dos anos, experiências que vão sendo armazenadas em nossa memória. Algumas memórias no plano individual são marcadas por momentos bons e ruins e ficam armazenadas em nosso inconsciente; estas, dependendo da ocasião, podem retornar a qualquer momento, seja pela emoção ou necessidade. Dantas $(2017$, p. 1) considera que:

A memória é o armazenamento de informaçôes e fatos obtidos através de experiências ouvidas ou vividas. Relaciona-se fortemente à aprendizagem que é a obtenção de novos conhecimentos, pois utiliza a memória para reter tais informaçôes no cérebro. Existem duas formas de adquirir e armazenar informaçóes:

Memória de Procedimento: Utilizada para armazenar e verificar informaçóes não verbalizadas como habilidades motoras, sensitivas ou intelectuais.

Memória Declarativa: Utilizada para armazenar e relembrar fatos e/ou dados recebidos pelos sentidos, criação de idéias, raciocínios [...].

Para Pollak (1992), a memória pode ser tanto individual quanto coletiva, pode sofrer variações dependendo do momento, pois os fenômenos históricos marcantes ficam no imaginário, podendo ser marcados por acontecimentos, pessoas e, até personagens que, em determinado

2 Para Squire (2014, p. 273) a "definição significa que narrativas podem implicar conjuntos de signos que se movimentam temporalmente, causalmente ou de alguma outra forma socioculturalmente reconhecível e que, por operarem com a particularidade e não com a generalidade, não são reduzíveis a teorias. Nesta definição, a narrativa pode operar em várias mídias, inclusive em imagens imóveis.", a definiçáo apesar de estar em movimento, pode sofrer modificaçóes em cada momento temporal. 
momento, podem retornar ao fato.

Em virtude dos inúmeros acontecimentos que se instalam na trajetória do indivíduo, com o tempo estes podem se solidificar ${ }^{3}$, construindo assim a memória coletiva, que muitas vezes é utilizada no meio político para justificar/construir um personagem marcante em determinados espaços de lugar e tempo ou até mesmo na construção da identidade do sujeito. Esta, segundo Pollak (1992), faz parte do processo de construção da identidade social agregada s à memória individual que reconstrói em si, instrumentos para a memória coletiva, que possui o compromisso de continuidade na base individual, das quais Barros (2009, p. 39), aponta:

Como conceito significativo para os recentes desenvolvimentos das ciências humanas, a noção de Memória tem sofrido ressignificaçóes bastante importantes. Para entendê-las, partiremos de algumas consideraçóes ainda sobre a Memória Individual, buscando perceber como certos modos de conceber a memória do indivíduo contaminaram, em algum momento, os modos de perceber a Memória Coletiva [...].

No campo do conhecimento científico principalmente das ciências humanas, o conceito de memória tem sofrido ressignificaçóes ${ }^{4}$, como aponta Barros (2009), com o termo "Memória Social", que delimita um campo de estudo e reflexôes pioneiras ao "Ensaio de Memórias Coletivas", de Maurice Halbwachs, em 1950, que adentrou os espaços acadêmicos, nas últimas décadas. No estudo das memórias deve-se ater a alguns critérios quando as utilizar como fonte de pesquisa.

\section{Consideraçóes finais}

É necessário, que a importância da memória para as instituições, manter um arquivo organizado da vida para as próximas pessoas que vierem a trabalhar nesses locais, podendo assim vislumbrar movimentos que ocorrem na instituição.

Uma das instituições mais visitadas e que possui arquivos de memória das pessoas, são as instituiçôes escolares, pois os dados documentais são a vida de cada estudante que ali esteve durante uma parte de sua vida. Por fim acreditamos que este texto possa contribuir com as pesquisas que verem abordar a temática, visto que é fundamental conhecermos cientificamente os processos institucionais relacionados a memória.

\section{Referências}

BARROS, José de Assunção. História e memória - uma relação na confluência entre tempo e espaço. Revista Mouseion, vol.3, n.5, jan-Jul/2009.

BOURDIEU, Pierre e PASSERON, Jean Claude, A reproduçáo: elementos para uma teoria do sistema de ensino. Rio de Janeiro, Francisco Alves, 1975.

COSTA, Icléia Thiesen Magalhães. Memória institucional: a construção conceitual numa abordagem teórico-metodológica. 1997. 169 f. Tese (Doutorado em Ciência da Informação) - Universidade Federal do Rio de Janeiro, Rio de Janeiro. 1997.

3 Neste caso em específico seria no sentido de permanecer. (Nota do autor)

4 A ressignificaçáo pode ser a mesma teoria de Saviani (2005), pois pode modificar em determinado tempo histórico. (Nota do autor) 
DANTAS, Gabriela Cabral da Silva. "Memória"; Brasil Escola. Disponível em <http:// brasilescola.uol.com.br/psicologia/memoria-1.htm>. Acesso em 20 de julho de 2017.

HOBSBAWM, Eric. Sobre História. São Paulo: Companhia das Letras, 1998.

MEZZANO, Alicia Corvalén de. Lembranças pessoais memórias institucionais: para uma metodologia de questionamento histórico-institucional. IN: BUTELMAN, Ida (org) Pensando as instituiçóes: teorias e práticas em educação. Porto Alegre: Artmed. p.35-66, 1998.

POLLAK, Michel. Memória e identidade social. estudos históricos. Rio de Janeiro, vol.5, n.10, p. 200-2012. 1992.

SAVIANI, Demerval. Instituiçóes escolares: conceito, história, historiografia e práticas. Cadernos de História da Educaçáo, n. 4, jan./dez, 2005.

SQUIRE, Corinne. O que é narrativa. Revista Civitas. Porto Alegre. v.14, no 2. P.272-284. Disponível em: <revistaseletronicas.pucrs.br/ojs/index.php/civitas/article/ download/17148/11473> acesso em 20 de agosto de 2018 .

TORRINHA, Francisco. Dicionário latino-português, 3aa ed. Porto, Marânus, 1945.

WERLE, Flávia Obino Corrêa. História das instituiçóes escolares: responsabilidade do gestor escolar. Cadernos de História da Educação, no 3 - jan/dez. p.109-119. 2004. 